\title{
Alemanes en el noroeste mexicano. Notas sobre su actividad comercial a inicios del siglo $\mathrm{XX}$
}

Germans in the Mexican Northwest. Notes on his commercial activity in early twentieth century

Jesús Méndez Reyes

Resumen

Palabras clave

Abstract

Key words
Investigador titular en el Instituto de Investigaciones Históricas de la Universidad Autónoma de Baja California. Realiza una estancia posdoctoral en la Universidad Nacional de Quilmes, Argentina, y es miembro del Sistema Nacional de Investigadores. Sus líneas recientes de investigación han sido la historia del crédito agrícola en México, el cooperativismo, la historia de las culturas políticas, la economía y el medio ambiente. Recientemente publicó “Industria eléctrica en Baja California: esfuerzo privado y regulación estatal, el caso de la Compañía Eléctrica y Telefónica Fronteriza, S. A. (1915-1943)" en M. Gámez (coord.), Electricidad: recurso estratégico y actividades productivas. Procesos de electrificación en el norte de México, siglos XIX-XX, México, El Colegio de San Luis, 2013. Su dirección de correo es: jmreyes@uabc.edu.mx.

La llegada de colonos centroeuropeos a Hispanoamérica data del siglo $\mathrm{XVI}$. Los actuales estados fronterizos del noroeste mexicano cuentan con numerosas comunidades de origen extranjero de añeja tradición. Tanto en Sonora como en la península de Baja California existen descendientes de alemanes que se consideran de reciente incorporación al país y no tienen claro el origen de sus familias, que arribaron en las postrimerías del siglo XIX e inicios del siglo XX. El propósito de este trabajo es referir la presencia y permanencia de la comunidad alemana en la historia del noroeste de México. Los comerciantes y empresarios que se reseñan, o sus descendientes, son una veta de futuros estudios para reconstruir la historia de esta comunidad y su integración a la sociedad fronteriza.

Migrantes alemanes, noroeste mexicano, comerciantes, empresarios, Baja California.

The arrival of migrants of Central and Eastern Europe to Latin America dates back to the sixteenth century. The current Northwest border states harbor foreign communities with time-honored traditions. There are many people from German descent in Sonora and in the Baja California peninsula, who are considered to be of recent incorporation to the country and are unaware of their family origins, which established themselves during the late nineteenth century and the beginning of the twentieth century. The purpose of this work is to recount the presence and permanency of the German community in the history of Northwestern Mexico. The merchants and entrepreneurs that are mentioned in this investigation, or their descendants, represent a vein for future studies in order to rebuild the history of this community and their integration to the border society.

German immigrants, Mexican Northwest, merchants, entrepreneurs, Baja California.

Recibido/Received 17 de mayo, 2013

Aprobado/Approved 


\title{
Alemanes en el noroeste mexicano Notas sobre su actividad comercial a inicios del siglo $\mathrm{XX}$
}

\author{
Jesús Méndez Reyes
}

Introducción

Entre 1846 y 1939 casi 60 millones de europeos salieron de sus países de origen para asentarse en Australia, Nueva Zelanda, África del Sur y a lo largo del continente americano en un éxodo que los estudiosos han llamado "la migración de masas", que sugiere que la emigración se debía a diversas razones no excluyentes entre sí. A saber, la miseria de la población y la dificultad para seguir dividiendo la propiedad rural entre los descendientes, la mejora de fortunas en el nuevo mundo, una respuesta a leyes naturales, el espíritu de aventura, favorecer la balanza de pagos o una política de expansión imperialista. ${ }^{1}$ La comunidad delengua alemana fue una de las primeras que se hizo visible y constante al emanciparse Nueva España de su metrópoli.

Horst Pietschmann traza una línea paralela entre el desmembramiento del Sacro Imperio Alemán (1806) y las posesiones americanas del imperio español, sobre todo Nueva España (1808-1810). Helmut Böhme, por su lado, sugiere que la salida de casi dos millones de personas de los ducados y territorios germánicos a lo largo del siglo XIX fue una respuesta al descontento popular, la falta de oportunidades y la constante movilidad de

1 Peter Stalker, Workers without frontiers: the impact of globalization on international migration, Boulder, Lynne Rienner, 2000, p. 4. La polémica no sólo fue "ideológica o retórica" operaban también intereses de grupos económicos "que calculaban los beneficios y perjuicios que el crecimiento de la inmigración les acarrearía”. Cfr. Fernando Devoto, Historia de la inmigración en la Argentina, Buenos Aires, Sudamericana, 2009, p. 51-52. 
sus habitantes después de la Revolución de 1848, la unificación alemana (1866-1870) y la industrialización del Reichstag. ${ }^{2}$

México abrió las puertas a los extranjeros para que residieran de manera temporal o permanente luego de la Independencia de España. El requisito fue que quienes llegasen provinieran de naciones cuyos gobiernos hubiesen aceptado de facto y de iure la emancipación de la nación mexicana. A partir del 1. de febrero de 1823, varios emigrantes europeos expresaron su deseo de establecerse de manera definitiva, entre ellos algunos de lengua alemana. El Ministerio de Relaciones Interiores y Exteriores de México contabilizó 987 emigrantes, 44 de éstos provenían de la Confederación Germánica. Hacia 1928 la suma de sajones y prusianos era de 108, y en la navidad de 1833, el viceconsulado de Matamoros reportó dos centenas de prusianos. ${ }^{3}$ ¿Prusianos, sajones, germanos, austriacos, alemanes? ¿Qué entiendo por alemanes o comunidad alemana en México a lo largo del siguiente trabajo? La palabra Deutsch, alemán, designaba a los pobladores que hablaban esa lengua en la parte oriental del Imperio Franco en el siglo VIII. El "pueblo alemán" se formó a partir de la afinidad de diferentes caseríos francos, sajones, suabos y bávaros- que con el tiempo compartieron la lengua, el carácter y el habitus alemán. Norbert Elias explica el término como "el saber social incorporado" de esa comunidad. Sin embargo, más allá de quienes habitaban el país de los alemanes (Deutschland), "la germanidad (Deutschtum: carácter o genio alemán) es una ideología étnica que coloca

2 Horst Pietschmann, "Paralelismos y percepciones mutuas en el proceso de formación de la representación político-democrática en México y Alemania en el primer tercio del siglo XIX” en Karl Kohut et al., Alemania y el México independiente. Percepciones mutuas, 1810-1910, México, Herder/Centro de Investigaciones y Estudios Superiores en Antropología Social/Universidad Nacional Autónoma de México/Universidad Iberoamericana/Cátedra Guillermo y Alejandro von Humboldt, 2010, p. 195-198. Helmut Böhme, "Prolegomena zu einer Sozial-und Wirschaftsgeschichte Deustchland im 19. und 20" en Jahrhundert, Frankfurt, 1968. Jonathan Steinberg, Bismarck, a life, Nueva York, Oxford University Press, 2011. Horts Stuke, The Economic History Review, New Series, v. 24, n. 2, 1971, p. 345. Steve Hochstadt, “Migration in Preindustrial Germany" en Conference Group for Central European History of the American Historical Association, www.jstor.org/stable/4545987, consultado el 27 de noviembre de 2012.

3 Jesús Méndez Reyes, “La Secretaría de Gobernación y el control político y económico en México durante el siglo XIX” en Historia de la Secretaría de Gobernación, México, Instituto Nacional de Estudios Históricos de la Revolución Mexicana, 2000, v. III, p. 159-183. Walther L. Bernecker, "Los alemanes en el México decimonónico: desde la Independencia hasta la Revolución de 1910” en Karl Kohut et al., Alemania, p. 296-298. 
el derecho de sangre como determinante de la nacionalidad por sobre el Estado y la ciudadanía”. Deutschtum responde al lenguaje, la apariencia, el antepasado familiar, el país de residencia y el de origen. "Alemanes son entonces personas de origen, idioma y cultura alemana, independientemente de la nacionalidad que hubieran tenido antes y después de la emigración a Latinoamérica". ${ }^{4}$

En este sentido, los personajes referidos en este texto fueron parte de ese habitus que conservaron al establecerse en Hermosillo, Ensenada, La Paz o San Diego, aun a sabiendas de que México era su segunda patria y de que sus hijos y esposas eran parte de una región particular en la que se desenvolvieron. El propósito de este trabajo es referir la presencia y permanencia de algunos alemanes en el noroeste de México a fines del siglo XIX e inicios del XX, particularmente en la península de Baja California. Por la temporalidad y el proceso histórico se contempla también a la comunidad alemana de la California mexicana, en particular a los que se quedaron en San Diego. Este avance de investigación, lejos de ser conclusivo, es un primer acercamiento a la llegada y establecimiento dealemanes en la península de Baja California. La escasa historiografía sobre extranjeros en la región ha privilegiado a los estadounidenses, los chinos y los japoneses, a pesar de la actividad y contribuciones de otras comunidades como las de origen hindú, italiano y alemán. El último apartado de este trabajo intenta "llenar el ojo" a los estudiosos de la región ante los testimonios y documentación que hay sobre alemanes en ambos lados de la frontera México-Estados Unidos.

\section{Los alemanes en México}

En la historiografía mexicana, Alexander von Humboldt ha sido el personaje mayormente referido cuando seabordan las relaciones y el intercambio entre uno y otro pueblo. En fechas recientes ha habido un esfuerzo académico por rescatar a otros actores, así como la historia de la reciprocidad México-Alemania. ${ }^{5}$ Me parece, sin embargo, que todavía hay un 
desbalance entre la historia de la comunidad alemana en la capital o el centro del país y las fronteras nortey sur de México, como ocurre con otros temas de la historia del país. En específico menciono las faenas comerciales y empresariales de la comunidad alemana en el norte de México, así como aquellos refugiados alemanes y austriacos que Gilberto Bosques y Manuel Ávila Camacho "salvaron" del nazismo entre 1940-1942 y se quedaron en estas latitudes. ${ }^{6}$

En este sentido, los debates contemporáneos sobre el fenómeno migratorio - como la teoría del pull-push (rechazo-atracción frente a mejores tierras, mejores oportunidades económicas, mejores libertades)- y la teoría económica de la migración discuten poco sobre la historia de las relaciones internacionales, los intercambios culturales de largo plazo y las actividades comerciales como parte de una realidad compleja y extensa entre los residentes y aquellos que llegan al país a integrarse o segregarse.

Volvamos a la comunidad germana en la historia de México. La crisis europea en las minas de plomo generó la salida de una gran cantidad de mineros alemanes hacia otros mercados laborales, algunos de éstos fueron contratados por las compañías inglesas para trabajar en México, al igual que numerosos científicos mineralogistas especializados en la extracción

brecha en el estudio de la comunidad alemana asentada en el país. Por ejemplo, los trabajos encabezados por Brígida von Mentz en el Instituto Nacional de Antropología e Historia y el Centro de Investigaciones y Estudios Superiores en Antropología Social; Walther L. Bernecker en El Colegio de México, así como el establecimiento en 1998 de la Cátedra Guillermo y Alejandro von Humboldt apoyada por la UNAM, El Colegio de México y la Deutscher Akademischer Austauschdienst (DAAD). Una revisión historiográfica de este proceso puede consultarse en Horst Pietschmann et al., Alemania y México: percepciones mutuas en impresos, siglos XVI-XVIII, México, Cátedra Guillermo y Alejandro Humboldt/Centro de Estudios de Historia de México Condumex/Fomento Cultural Banamex/Universidad Iberoamericana, 2005. Ricardo Pérez Montfort, “Un siglo y medio de presencia germana en la capital”, en Carlos Martínez Assad (coord.), La ciudad cosmopolita de los inmigrantes, México, Gobierno del Distrito Federal, 2009, t. II, p. 39-73.

6 Hacia 1942 llegaron al puerto de Veracruz otros 1500 alemanes huyendo del régimen nazi, judíos, austriacos, checos, miembros del Partido Comunista Alemán (KPD) y asilados políticos. Vid. Archivo General de la Nación (en adelante, AGN), Fondo Departamento de Migración, Sección Alemanes. Delia Salazar, Las cuentas de los sueños. La presencia extranjera en México a través de las estadística nacionales, 1880-1914, México, Secretaría de Gobernación, Instituto Nacional de Migración/Instituto Nacional de Antropología e Historia, 2010, p. 226; Yetlaneci Alcaraz, “Huida a México”, Proceso, n. 1888, 6 de enero de 2013, p. 48-51. 
de plata provenientes de Sajonia, Harz y la región de Sieger. Uno de los contratistas de esa mano de obra fue la famosa Deustsch-Amerikanischer Bergwerksverein (Compañía Mexicana de Minas), que explotó las minas de los actuales estados de México, Hidalgo y Michoacán. ${ }^{7}$ Los afanes expansionistas de Alemania fueron evidentes a partir del proceso de Independencia de México $^{8}$ y se aceleraron en las décadas ulteriores.

La prometida libertad comercial de los insurgentes no fue inmediata pero abrió la puerta al lino, la seda, los paños y otras mercaderías con el pago correspondiente de aranceles. En contraparte, el proteccionismo comercial continuó durante el primer tercio del siglo XIX y el bloqueo continental de Napoleón ahorcó las exportaciones prusianas hacia el nuevo mundo, al menos hasta la revolución de 1848. Este evento motivó otra oleada de migrantes y refugiados conocidos como "los 48's", 9 mientras que el comercio entre México y Alemania crecía de manera significativa. Los puertos hanseáticos remitían textiles y ferretería, en tanto que México exportaba algodón y minerales preciosos. ${ }^{10}$

Este ir y venir facilitó la firma del Tratado de Amistad, Navegación y Comercio entre México y Hannover en junio de 1827 y con las ciudades hanseáticas de Lübeck, Bremen y Hamburgo en 1841. Las fuentes documentales registran que para 1831 salían en promedio 22 buques de Hamburgo hacia los puertos mexicanos y 47 vapores de México hacia el puerto hamburgués. Esto no significa que transportaran productos nacionales o

7 Brígida von Mentz, “Tecnología minera alemana en México durante la primera mitad del siglo XIX”, Estudios de Historia Moderna y Contemporánea, v. 8, 1980, p. 85-95. Walther L. Bernecker, "Los alemanes en el México decimonónico: desde la Independencia hasta la Revolución de 1910” en Karl Kohut et al., Alemania, p. 295.

8 Walther L. Bernecker, "Las relaciones comerciales germano-mexicanas en el siglo XIX” en León Bieber (coord.), Las relaciones germano-mexicanas desde el aporte de los hermanos Humboldt hasta el presente, México, El Colegio de México/Universidad Nacional Autónoma de México, Facultad de Filosofía y Letras, 2002, p. 92-94.

9 Elizabeth Reinbold MacPhail, The influence of German immigrants on the growth of San Diego, San Diego, San Diego Historical Society, 1986, p. 12.

10 Entre otros productos destacaron los linos, las sedas y las cintas de algodón; paño, sombreros, nanquín, ferretería y peltre, relojes, latón y lámina de latón, sables, instrumentos musicales, papel y vidrio, naipes, agujas y quincalla en general. Cfr. Hendrik Dane, Die wirtschaftlichen Beziehungen Deustschlands zu Mexiko und Mittelamerica im 19 Jahrhundert, Colonia, Böhlau Verlag, 1971. 
fuesen a tope los almacenes y mamparos de las embarcaciones, pero es un dato relevante del intercambio y las desavenencias históricas entre los dos pueblos. ${ }^{11}$ Es notorio que entre 1830 y la guerra de Reforma (1857-1861) hubo prestamistas y agiotistas de origen alemán con fuerte presencia en México, como Guillermo Silem, Enrique Virmond, Germán Nolte, Federico Hube, Francisco Schneider y la Casa Benecke y Compañía. Algunos de estos personajes fueron parte de los acreedores que se encresparon por la suspensión de pagos dela deuda pública ordenada por Santa Anna en 1842 y entre los 170 acreedores que signaron la Representación correspondiente de queja aparecen siete alemanes. ${ }^{12}$

Empero, el prestamista alemán de mayor osadía fue Guillermo de Drusina, casado con María de la Cruz Noriega y Vicario - mexicana acaudalada quien lo nombró su apoderado- y socio de Gregorio J. Martínez del Río, uno de los agiotistas y hombre de negocios más alevosos de la primera mitad del XIX. Drusina se encargó de colocar capital inglés, francés y mexicano durante las presidencias de Antonio López de Santa Anna así como prestar efectivo a la Iglesia, a los hacendados con problemas hipotecarios y al Supremo Gobierno durante la guerra contra Estados Unidos. Al medio millón de pesos que el gobierno nacional le debía a Drusina, se sumaron los gastos de guarnición de la aduana de Veracruz, las conductas comerciales hacia San Luis Potosí y la quinta parte de derecho de exportación del algodón y bonos públicos al 26 por ciento, que sumaron 1880000 pesos, ¡una cifra impagable para la época! Poco antes de la revuelta de Ayutla, Drusina fungió como propietario de fincas rurales en Zamora y Morelia,

11 El encargado de negocios de México para los asuntos con Sajonia y Prusia, Thomas Murphy, no fue recibido en Berlín y debió establecerse en París entre febrero de 1832 y mediados de 1833; en agosto de ese año fue sustituido por el general José Ignacio Basadre, ministro plenipotenciario para asuntos mexicanos en Prusia, Sajonia y la Confederación Germánica. En 1872 Alemania era el cuarto exportador de mercaderías a México; en 2011, Alemania ocupaba el séptimo lugar como socio comercial de México. Jesús Méndez Reyes, “Alemania y México: una relación histórica. La influencia alemana en el cooperativismo y el crédito agrario en México", Matices Zeitschrift zu Lateinamerika, Spanien und Portugal, n. 64, (Colonia) 1, 2010, p. 8-10.

12 Rosa María Meyer, "El estilo empresarial de especular. Nacionalidad y finanzas a mediados del siglo XIX” en Rosa María Meyer et al., La inmigrantes en el mundo de los negocios, México, Plaza y Valdés/Consejo Nacional para la Cultura y las Artes/Instituto Nacional de Antropología e Historia, 2003, p. 77-91. Brígida von Mentz et al., Los pioneros, p. 106-120. 
en Guanajuato, Veracruz, así como Tuxtla y el Soconusco, en Chiapas. A pesar de todo lo anterior, la casa de Guillermo de Drusina se declaró en bancarrota al iniciar la década $1850 .^{13}$

Al triunfo de la revuelta de Ayutla, Alemania perdió terreno frente a franceses eingleses, aunque - según el cónsul prusiano Benecke- los mexicanos siguieron prefiriendo los terciopelos, chales, medias, calcetines, pañuelos, telas de dril y mercería alemanas (cuadro 1). Para este momento "el comercio de ferretería pertenecía por completo a los alemanes en México" al igual que los muebles y menaje de casa que "se vendían estupendamente”. Tras la unificación de Alemania y el progreso logrado por el canciller Otto von Bismarck, el imperio alemán exportó capitales hacia América Latina en el orden de 1473 millones de dólares de la época, colocándose para 1880 como el tercer inversor en la región. $\mathrm{Al}$ aumento de las casas de comercio alemanas y la venta minorista de particulares, siguieron las grandes inversiones en la minería, la industria eléctrica (Siemens-Halske), la ganadería, la industria química, el sistema financiero -Deustche Bank, Disconto Gesellschaft y Dresdner Bank-, el comercio y la compra de bonos públicos en el último cuarto del siglo XIX.

Del medio millar de alemanes residentes en México a finales de ese siglo, unos se integraron a redes políticas y familiares de la aristocracia regional, a círculos literarios, institutos científicos, asociaciones culturales y a la prensa citadina. ${ }^{14} \mathrm{Al}$ estallar la Revolución mexicana, la inversión directa alemana representó sólo el 6 por ciento del total de la balanza comercial mexicana, el 13 por ciento delas importaciones y el 3 por ciento de las exportaciones ¿Qué ocurrió al iniciar el siglo XX con la comunidad alemana? En una declaración al Reichstag, por parte del ministro de Relaciones Exteriores de Alemania, Gottlieb von J agow, éste valoró que no había grandes pérdidas en las propiedades germanas ni aumento de inversiones

13 Cfr. Von Mentz et al., Los pioneros, p. 112-118.

14 V. g. el científico Isidoro Epstein reconocido por sus estudios topográficos, estadísticos, lingüísticos y literarios, profesor de matemáticas y alemán, física, agrimensura, mecánica y didáctica en Zacatecas, Aguascalientes, Monterrey y Texas. Editó también numerosos periódicos, como Germania, Vorwärts, El Atalaya, El Jornalero de la Prensa, El Precursor, La Luz del Siglo y El Mexicano de Texas, este último en idioma español con "bastante fama en Estados Unidos y México". Cfr. Lilia Vieyra y Alejandro Vigil, “Isidoro Epstein: un alemán en México (1851-1894)”, Boletín, v. XI, n. 1 y 2, 2006, p. 65-110. 
Cuadro 1. Algunas casas comerciales alemanas establecidas en la ciudad de México, 1871-1872

\begin{tabular}{|l|l|l|l|}
\hline \multicolumn{1}{|c|}{ Nombre } & \multicolumn{1}{|c|}{ Oferta comercial } & \multicolumn{1}{c|}{ Nombre } & \multicolumn{1}{c|}{ Oferta comercial } \\
\hline Casa Boker* & $\begin{array}{l}\text { Mercería, alimentos, } \\
\text { cigarros, armas, metales, } \\
\text { maquinaria pesada. }\end{array}$ & Haghenbeck & $\begin{array}{l}\text { Mercería, drogas, } \\
\text { perfumería. }\end{array}$ \\
\hline Benecke y Compañía & $\begin{array}{l}\text { Mercería, cueros, café, } \\
\text { cacao, cáñamo. }\end{array}$ & Leuthner & $\begin{array}{l}\text { Ferretería, cueros, pelo de } \\
\text { conejo. }\end{array}$ \\
\hline Bonne \& Ebert & $\begin{array}{l}\text { Ferretería, productos } \\
\text { agropecuarios, textiles. }\end{array}$ & Lüdert & $\begin{array}{l}\text { Ferretería, productos } \\
\text { agropecuarios, textiles. }\end{array}$ \\
\hline Brehm \& Rübke & $\begin{array}{l}\text { Ferretería, seda, tabaco, } \\
\text { algodón, petróleo. }\end{array}$ & $\begin{array}{l}\text { Nagel y Compañía, } \\
\text { Sucs. }\end{array}$ & $\begin{array}{l}\text { Mercería, alimentos, } \\
\text { cigarros, vinos, drogas. }\end{array}$ \\
\hline $\begin{array}{l}\text { Fischer y Compañía, } \\
\text { Sucs. }\end{array}$ & Ferretería, mercería. & Phillip \& Rennow & Textiles y otros. \\
\hline $\begin{array}{l}\text { Kaufmann, Graue y } \\
\text { Compañía }\end{array}$ & $\begin{array}{l}\text { Textiles, alimentos, cigarros, } \\
\text { papel, libros. }\end{array}$ & Wagner \& Levien & $\begin{array}{l}\text { Papel, vidrio, instrumen- } \\
\text { tos musicales. }\end{array}$ \\
\hline Martin \& Daran & $\begin{array}{l}\text { Ferretería, mercería, vinos y y } \\
\text { licores, papel. }\end{array}$ & $\begin{array}{l}\text { Wiesel, Degres y } \\
\text { Compañía, Sucs. }\end{array}$ & $\begin{array}{l}\text { Alimentos, cigarros, } \\
\text { metales, armas, libros. }\end{array}$ \\
\hline Mazarraza \& Schultzz & $\begin{array}{l}\text { Textiles, alimentos, vinos y } \\
\text { licores. }\end{array}$ & Wyngaert & Drogas y perfumería. \\
\hline Uhilein Sucs. & Cristal, vidrio, loza. & Zivy & $\begin{array}{l}\text { Papel, libros, drogas, } \\
\text { perfumería, joyería. }\end{array}$ \\
\hline
\end{tabular}

* La Casa Boker o Compañía Ferretera Nacional durante los últimos años del Porfiriato se caracterizó por su imponente edificio del que todavía se encuentran vestigios en la esquina de 16 de Septiembre e Isabel la Católica, en la ciudad de México. Drogas = botica y/o farmacia.

FUENTE: Elaboración a partir de B. von Mentz et al., Los pioneros, p. 81-83, y R. Pérez Montfort, Un siglo y medio, p. 44, 51.

para 1914. ${ }^{15} \mathrm{La}$ Gran Guerra frenó la salida de personas y capitales pero sin que México dejara de ser un destino importante para la comunidad centroeuropea, por ejemplo el doctor Karl Gehrmann, perito en materia agrícola que llegó a México a través de la Legación del Imperio Alemán. ${ }^{16}$ En las siguientes décadas, el periodo de entreguerras, las razones de emigración tuvieron otras razones, como el asilo político y el rescate de grupos perseguidos.

15 Friedrich Katz, La guerra secreta en México, 2 v., México, Era, 1982, v. I, p. 378.

16 Solicitó estudiar la agricultura mexicana y anudar relaciones con los principales institutos nacionales dedicados a ese ramo económico. Carta de N. von Eckardt, enviado extraordinario y ministro plenipotenciario de Alemania en México al general de división Cándido Aguilar, secretario de Relaciones Exteriores, 22 de marzo de 1917, Archivo Histórico de la Secretaría de Relaciones Exteriores Genaro Estrada (en adelante, ASRE-GE), exp. 17-9-262, f. 2-5. 
En este sentido, la intención primigenia de este estudio fue ubicar a personajes que permitieran reconstruir la historia económica de la región y hallamos muchas más pistas. Al pergeñar y sistematizar las fuentes documentales, el herramental metodológico privilegiaría a comerciantes, transportistas, empresarios e industriales que dieran cuenta de la presencia alemana en el noroeste del país, en consonancia con lo afirmado por Brígida von Mentz -que a México "nunca llegaron alemanes pobres" sino representantes del "capital comercial e industrial alemán". ${ }^{17}$

La base de datos que comenzamos a elaborar con fuentes de archivos nacionales y regionales evidenció tareas menos pretenciosas de los emigrantes o los visitantes. Las fichas documentales, pasaportes, registro de extranjeros, informes y otra documentación oficial nos arrojó agricultores, cerrajeros, ebanistas, cocineros, agricultores, impresores, peleteros, maestros cerveceros. Asimismo el registro de "asilados políticos" y "visitantes" que declaraban ser bailarines, dentistas, camareros, curtidores, estudiantes, pescadores, químicos, rentistas, retocadores y uno que otro banquero o industrial. Apareció también un buen número de mujeres institutrices, estudiantes, amas de casa, "solteras", artistas, así como mexicanas, esposas de profesionistas o de aprendices, que por ley adoptaban la nacionalidad del cónyuge.

La muestra estadística o la base de datos no está incluida en este artículo, ${ }^{18}$ pues rebasa el corte temporal del mismo y el propósito primordial del artículo es proveer de algunas pistas a futuras investigaciones

17 Aclaro que tiempo después la investigadora suavizó la caracterización de la emigración alemana. Como en todo el siglo XIX mexicano, la llegada de grupos de extranjeros fue parte de la "movilidad social" de las "clases medias [y de] personas bastante comunes", entre los que hay que incluir a los alemanes que se quedaron en el país. Brígida von Mentz et al., Los pioneros del imperialismo alemán en México, México, Centro de Investigaciones y Estudios Superiores en Antropología Social, Ediciones de la Casa Chata, 1982, p. 14. Brígida von Mentz (coord.), Movilidad social de sectores medios en México. Una retrospectiva histórica. siglos XVII al XX, México, Centro de Investigaciones y Estudios Superiores en Antropología Social/Miguel Ángel Porrúa, 2003, p. 7-8, 22 y 149-160.

18 Para el rescate de las fuentes de archivo, digitalización y formación de una base de datos conté con el apoyo de Natalia Espinosa, J. Luis Gallegos, Sinuhé Guevara, Carlos A. Piña y Abraham Uribe, en ese momento estudiantes de la licenciatura en Historia de la UABC. Los recursos financieros para esta tarea provinieron del Departamento de Posgrado e Investigación de la misma universidad que financió un proyecto del Cuerpo Académico Historia y Sociedad al que estuve asociado entre los años 2008 y 2011. 
sobre los extranjeros en la antigua California mexicana, la actual península de Baja California y su circuito comercial histórico: Sonora, Sinaloa y el Pacífico.

El asentamiento alemán en el noroeste mexicano

Los extranjeros en el norte del país se dedicaron al desarrollo de diferentes actividades, en ocasiones similares a las que desempeñaban en sus países de origen. Durante el primer tercio del siglo XIX los puertos de Tampico, Veracruz y Sisal fueron los portones de entrada de mercancía y emigrantes, así como de buena parte del contrabando, luego vendrían los puertos con salida al Pacífico. ${ }^{19}$ En este encuentro comercial, el norte del país registró la presencia de alemanes por dos vías: la tradicional, Europa-Veracruz-Tampico y su ulterior internación a lo largo de la república mexicana. La segunda, el alto Atlántico (Boston y Nueva York), los estados fronterizos del norte y el Pacífico mexicano. Esta última vía -del oriente de Estados Unidos hacia el suroeste de la nación americana- se aceleró con la apertura del Ferrocarril Central y de ahí a los poblados fronterizos con México para comercio, búsqueda de oro, paseo o establecimiento de manera definitiva.

Así ocurrió en El Paso, Texas, residencia para un buen número de empresarios judíos alemanes que, desde Chicago y Nueva York, vieron gran potencial en la frontera con México. A ellos se debió la instalación de los negocios de mayor pujanza en la ciudad, merced al clima benigno que les permitió recuperarse de la tuberculosis o el asma que los aquejaba. Tal fue el caso del doctor R. B. Homan y el cirujano dentista John C. Crimman”. ${ }^{20}$

Asimismo, los informes consulares prusianos señalan que la ciudad portuaria de Brownsville era "el depósito detodas las mercancías prohibidas

19 El cónsul francés Alexander Martin estimó en 25 ciento del valor total del comercio exterior mexicano para 1827. José María Luis Mora argumentó por esos años que “dos terceras partes de todos los bienes de consumo" no pagaban aranceles de importación. Por su parte, Bernecker refiere que el contrabando era mucho más extenso en la larga costa del Pacífico, y para mitad del siglo, Guaymas era "un emporio de los contrabandistas de metales preciosos" porque, según, no había ninguna casa de moneda.

20 Carlos González Herrera, "De Franklin a El Paso. La transformación de un asentamiento mexicano en una ciudad angloamericana: 1850-1910" en Jorge Chávez (comp.), Visiones de la frontera, México, Universidad Autónoma de Ciudad Juárez, 2010, p. 65 y 71-72. 
destinadas a ingresar clandestinamente a México". Éstas se trasladaban por la orilla izquierda del río Bravo; de ahí se movían a Monterrey, Coahuila, Zacatecas y San Luis Potosí. Mientras del lado del Océano Pacífico, los puertos de Acapulco, Mazatlán y San Blas, Manzanillo, Guaymas y La Paz fueron aprovechados también por los comerciantes alemanes establecidos y por aquellos que se dedicaban al contrabando.

Referí en el apartado anterior que el sentimiento alemán se experimentó con fuerza después de la unificación alemana (1871), justo cuando llegaron grupos importantes al noroeste mexicano o consolidaron su presencia económica en Jalisco, Colima, Chiapas, Yucatán y Centroamérica. ${ }^{21}$ Hacia 1879 "se institucionalizó una conexión directa entre Hamburgo y los puertos mexicanos de Tampico, Veracruz y Progreso", de suerte que el valor total de las exportaciones mexicanas a Alemania sumó un millón de pesos oro y las importaciones desde Alemania 443000 pesos oro. ${ }^{22}$ Es decir: hubo saldo positivo en la balanza comercial a favor de México.

La presencia germana se extendía a lo largo del país de manera sigilosa pero constante. Isabel Monroy registra una lista de comerciantes, mineros y artesanos alemanes que en su mayoría se quedaron en México, entre otros, Enrique Fugemann, Francisco Hartog, Federico Hohlt, Guillermo Droege y Juan Ermert. ${ }^{23}$ Destacó Benjamin Degateau, quien acre-

21 Julio Castellanos, El imperialismo alemán en Guatemala. El Tratado de Comercio de 1887, Guatemala, Universidad San Carlos de Guatemala, Instituto de Investigaciones Económicas y Sociales, 1977. Pablo Serrano Álvarez, “Hacendados, comerciantes y empresarios extranjeros en Colima, 1857-1914”, Revista del Seminario de Historia Mexicana, v. III, n. 2, verano 2002. Servando Ortoll, Las conquistas y desventuras de un cónsul y hacendado alemán en Colima, Hermosillo, El Colegio de Sonora, 2005. José Rafael Sáenz Rangel, “La población alemana en Colima durante el Porfiriato: profesión e integración a la economía regional” en J. Carlos Reyes G. (ed.), Memoria del III Foro Colima y su Región. Arqueología, antropología e historia, México, Gobierno del Estado de Colima, Secretaría de Cultura, 2007. Alma Durán-Merk, Identifying Villa Carlota: German settlements in Yucatán, Mexico, during the Second Mexican Empire 1864-1867, Augsburg, Universität Augsburg, 2007. Consuelo Delgado C. y J. Rafael Sáenz R., "La oligarquía empresarial alemana en Colima, siglos XIX y XX" en Memoria del IV Foro Colima y su Región. Arqueología, antropología e historia, México, Gobierno del Estado de Colima, Secretaría de Cultura, 2008.

22 Walther L. Bernecker, Alemania y México, p. 67.

23 María Isabel Monroy Castillo, Sueños, tentativas y posibilidades. Extranjeros en San Luis Potosí, 1821-1845, México, El Colegio de San Luis/Archivo Histórico del Estado de San Luis Potosí, 2004, p. 387-405. 
centó su fortuna por el contrabando de algodón durante la guerra de Secesión en Estados Unidos y las remesas de moneda hacia puertos europeos. Degateau se mudó hacia el norte central de México, junto con su hermano Emilio. En Casas Grandes, Chihuahua, los hermanos Degateau abrieron una "tienda de menudeo y mayoreo", una fábrica de hilados en la capital y una hacienda agroganadera en Camargo. ${ }^{24}$ En 1877, Benjamin Degateau fue nombrado vicecónsul alemán en Chihuahua.

A finales del Porfiriato, la cláusula de nación más favorecida diversificó las inversiones alemanas al sector bancario (Bleichröeder) y las industrias del vidrio, el hierro y el armamento (Krupp), la ganadería, la peletería, la minería y el mercado de tierras a través de la plantación. ${ }^{25} \mathrm{En}$ este sentido, las políticas de colonización de las administraciones liberales facilitaron el establecimiento y el tránsito de las diversas comunidades extranjeras. Ignacio Comonfort pretendió establecer una colonia de alemanes en Lampazos, Nuevo León, en los terrenos donados por Gregorio Mier y Terán a mitad del siglo XIX. La colonia “debía tener tierras irrigadas a dividirse en 800 lotes, 500 serían para alemanes, 250 para mexicanos y 50 para propios de la comunidad". ${ }^{26}$

Por su parte, la administración de Porfirio Díaz llevó colonos estadounidenses a El Fuerte, Sinaloa; griegos al puerto de Mazatlán; coreanos a Yucatán, y en el tránsito de los siglos XIX-XX franceses, chinos, japoneses, rusos, italianos y alemanes a lo largo de la península de Baja California. Romero Gil refiere que los británicos hicieron del noroeste "un mercado cautivo para sus manufacturas, obteniendo a cambio importantes remesas de metales preciosos".

La Ley de Extranjería y Naturalización de 1886 dio cierto orden al registro de inmigrantes por las aduanas marítimas y terrestres. Esto permitió organizar la estadística y dar cuenta de la febril actividad de extranjeros en el país, incluida la colonia alemana. Por ejemplo, los comerciantes del centro-occidente de México - los J urgensen, Kunhardt, Hachar, Collig-

24 Jane-Dale Lloyd, Cinco ensayos sobre cultura material de rancheros y medieros del noroeste de Chihuahua, 1886-1910, México, Universidad Iberoamericana, 2001, p. 109.

25 Friedrich Katz, La guerra secreta en México, v. I, p. 72. Walther L. Bernecker, Los alemanes, p. 308-311. Walther L. Bernecker, Alemania y México, 2005, p. 6.

26 María Cristina Torales, "La colonia alemana en la capital mexicana decimonónica. La construcción de su imagen pública” en Karl Kohut et al., Alemania, p. 320. 
non, Hohner y Hering- los latifundistas de las fincas cafetaleras del suroeste: Motozintla, Mexcalapa, el Suchiate, Tapachula, Mariscal y Guatemala, así como los emprendedores del noroeste del país -los Müller, Bley, Bruckner, Hoeffer, Bülle, Gerhart, Goldbaum, Cohen, Marburg, Ibs, Dato, Hoffman y Hussong. ${ }^{27}$

Hacia 1895 residían en México 2420 alemanes de manera oficial; según el censo de 1910, su número alcanzó 4000 residentes. En términos comparativos, los alemanes en el país representaban más del total de habitantes de algunos de los poblados de la península de Baja California, como La Paz, Loreto o Real del Castillo, que apenas alcanzaban o rebasaban el millar de pobladores en cada uno. Según George Ryerson, los alemanes y noruegos eran "los que más convenían a este rico y poco explotado territorio" de Baja California, donde pueden encontrarse mineros, agricultores, artesanos y gente emprendedora de toda clase de negocios. ${ }^{28}$

De este modo, la comunidad alemana comenzó a establecerse en el noroeste de México, a lo largo de las poblaciones de Sinaloa, Sonora y la península de Baja California, amén de algunos otros que llegaron provenientes de Estados Unidos, en la oleada de alemanes que movieron los ferrocarriles de un extremo a otro de la Unión Americana. En el tránsito de los siglos XIX al XX, numerosas empresas de capital alemán se inscribirían en el registro público de la propiedad de Hermosillo -Julieta López Griego estudia algunos casos (cuadro 2)- y durante los primeros años de la centuria se establecieron vínculos entre alemanes en Sonora y Baja California. El proceder clásico fue a través del matrimonio y el registro de sociedades en comandita o sociedades anónimas. Estallada la Revolución, los nodos de las redes sociales fueron la argamasa para evitar la dispersión de capitales.

27 Sergio Valerio Ulloa, Los empresarios extranjeros en Guadalajara durante el Porfiriato, Guadalajara, Universidad de Guadalajara, 2002. Julieta López Griego y J. Méndez Reyes, “Alemanes en el noroeste mexicano: redes empresariales en Sonora y Baja California a fines del XIX. Una aproximación" en XXIV Simposio de Historia, Sociedad Sonorense de Historia, A. C., Hermosillo, Sonora, noviembre de 2011, inédito. Alma Durán-Merk, op. cit.

28 Delia Salazar, op. cit., p. 73 y 231. 
Cuadro 2. Algunas empresas y negocios de capital y/o participación alemana en Sonora, 1890-1920 (Pesos y dólares de la época)

\begin{tabular}{|c|c|c|c|}
\hline Nombre & Capital social & Nombre & Capital social \\
\hline A. Bülle y Compañía, S. en C. & 3600 & El Oro Mining Company, S. A. & 10000 dólares \\
\hline $\begin{array}{l}\text { Astiazarán, Seldner y } \\
\text { Compañía- Mercería de la Paz, } \\
\text { S. N. C. }\end{array}$ & 15000 & F. Seldner y Compañía, S. N. C. & 1000 \\
\hline Banco de Sonora, S. A. & 1500000 & $\begin{array}{l}\text { Fábrica de Galletas } \\
\text { Cuauhtémoc, S. A. }\end{array}$ & 25000 \\
\hline $\begin{array}{l}\text { Banco Hipotecario y Agrícola } \\
\text { del Pacífico, S. A. }\end{array}$ & 2000000 & $\begin{array}{l}\text { Fábrica de Hielo El Progreso, } \\
\text { S. N. C. }\end{array}$ & 7500 \\
\hline $\begin{array}{l}\text { Bristol Mercantile Company, } \\
\text { S. en C. }\end{array}$ & 10000 & $\begin{array}{l}\text { G. Möller y Compañía, S. N. } \\
\text { C. }\end{array}$ & 50000 \\
\hline Cervecería de Sonora, S. A. & 710000 & G. Zaragoza, S. en C. & 75000 \\
\hline $\begin{array}{l}\text { Cohen Hermanos Sucesores, } \\
\text { S. N. C. }\end{array}$ & 5000 & $\begin{array}{l}\text { Grand Central Mining and } \\
\text { Milling Company Limit., S. A. }\end{array}$ & 48000 \\
\hline $\begin{array}{l}\text { Compañía de Cobre Arizpe, } \\
\text { S. A. }\end{array}$ & 100000 & $\begin{array}{l}\text { H. Wolf y Compañía-La } \\
\text { Novedad, S. N. C. }\end{array}$ & 50000 \\
\hline $\begin{array}{l}\text { Compañía de Irrigación del } \\
\text { Yaqui, S. A. }\end{array}$ & 60000 & $\begin{array}{l}\text { H. Wolf y Compañía (antes } \\
\text { Herman Wolf y Cía.), S. N. C. }\end{array}$ & 50000 \\
\hline $\begin{array}{l}\text { Compañía Destiladora de } \\
\text { Whiskey de Sonora, S. A. }\end{array}$ & 16000 & Heise y Zuccoli, S. N. C. & 2000 \\
\hline $\begin{array}{l}\text { Compañía Exploradora de } \\
\text { Altar- Foucault y Compañía, } \\
\text { S. N. C. }\end{array}$ & 6666 & $\begin{array}{l}\text { Hermosillo Fluor Milling } \\
\text { Company, S. N. C. }\end{array}$ & 50000 \\
\hline $\begin{array}{l}\text { Compañía Explotadora de las } \\
\text { Salinas de El Cocherito, S. A. }\end{array}$ & 50000 & Hoffmann y Miranda, S. N. C. & 8000 \\
\hline $\begin{array}{l}\text { Compañía Explotadora de } \\
\text { Occidente, S. A. }\end{array}$ & 75000 & $\begin{array}{l}\text { *La Sonorense Fábrica de } \\
\text { Galletas, S. A. }\end{array}$ & 52000 \\
\hline $\begin{array}{l}\text { Compañía Explotadora de } \\
\text { Tierras y Maderas, S. A. }\end{array}$ & 400000 & $\begin{array}{l}\text { La Ventura Mining Company, } \\
\text { S. A. }\end{array}$ & 25000 \\
\hline $\begin{array}{l}\text { Compañía Ganadera Los } \\
\text { Pozos, S. A. }\end{array}$ & 5000 & La Verde Mining Co., S. A. & 10000 \\
\hline $\begin{array}{l}\text { Compañía Industrial de } \\
\text { Álamos, S. A. }\end{array}$ & 80000 & Lajuela Copper Co., S. A. & 20000 \\
\hline $\begin{array}{l}\text { Compañía industrial de } \\
\text { Navojoa, S. A. }\end{array}$ & $10000^{* *}$ & Levy y Fraeber, S. N. C. & 1000 \\
\hline $\begin{array}{l}\text { Compañía Industrial de } \\
\text { Sonora, S. N. C. }\end{array}$ & 20000 & $\begin{array}{l}\text { Línea de Navegación del } \\
\text { Pacífico, S. A. }\end{array}$ & 100000 \\
\hline $\begin{array}{l}\text { Compañía Industrial del } \\
\text { Pacífico, S. A } \\
\text { "Los Ángeles", S. A. }\end{array}$ & 1000000 & $\begin{array}{l}\text { Mercería de la Paz, Bley } \\
\text { Hermanos, S. N. C. }\end{array}$ & 20000 \\
\hline
\end{tabular}


Cuadro 2. Algunas empresas y negocios de capital (continuación)

\begin{tabular}{|c|c|c|c|}
\hline Nombre & Capital social & Nombre & Capital social \\
\hline $\begin{array}{l}\text { Compañía Jabonera del } \\
\text { Pacífico, S. A. }\end{array}$ & 65000 & Mexican Metals Co., S.A. & 10000 \\
\hline $\begin{array}{l}\text { Compañía Ladrillera de } \\
\text { Sonora, S. A. }\end{array}$ & 50000 & $\begin{array}{l}\text { Miguel Latz y Hermano, } \\
\text { S. N. C. }\end{array}$ & 30000 \\
\hline $\begin{array}{l}\text { Compañía Metalúrgica y } \\
\text { Refinadora del Pacífico, S. A. }\end{array}$ & 1000000 & $\begin{array}{l}\text { Mina Grande Mining } \\
\text { Company, S. A. }\end{array}$ & 10000 \\
\hline $\begin{array}{l}\text { Compañía Minera Bertha y } \\
\text { Donato Guerra, S. A. }\end{array}$ & 24000 & $\begin{array}{l}\text { Minnesota \& Mexican } \\
\text { Mining and Develpoment } \\
\text { Co., S. A. }\end{array}$ & $10000 * *$ \\
\hline $\begin{array}{l}\text { Compañía Minera de Carbó, } \\
\text { S. A. }\end{array}$ & 12000 & $\begin{array}{l}\text { Pedro Cosca y Compañía, } \\
\text { S. en C. }\end{array}$ & 30000 \\
\hline $\begin{array}{l}\text { Compañía Minera de Cerro } \\
\text { Verde, S.A. }\end{array}$ & 10000 & $\begin{array}{l}\text { Rademacher, Müller y } \\
\text { Compañía - La Constancia, } \\
\text { S. en C. }\end{array}$ & 120000 \\
\hline $\begin{array}{l}\text { Compañía Minera de San } \\
\text { Julián, S. A. }\end{array}$ & $50000 * *$ & $\begin{array}{l}\text { Samuel H. Kraft y Compañía, } \\
\text { S. en C. }\end{array}$ & 200 \\
\hline $\begin{array}{l}\text { Compañía Minera de Santa } \\
\text { Rosalía, S. A. }\end{array}$ & 2000 & Seldner y Von Borstel, S. A. & 20000 \\
\hline $\begin{array}{l}\text { Compañía Minera Estrella del } \\
\text { Norte, S. A. }\end{array}$ & 2000 & $\begin{array}{l}\text { Sociedad Cooperativa de } \\
\text { Ahorros e Inversión de } \\
\text { Sonora Limit., S.C. }\end{array}$ & 500000 \\
\hline $\begin{array}{l}\text { Compañía Minera Gloria y } \\
\text { Fortuna Consolidada, S. A. }\end{array}$ & 24000 & $\begin{array}{l}\text { Sociedad Agrícola de } \\
\text { Caborca, S. A. }\end{array}$ & 25000 \\
\hline $\begin{array}{l}\text { Compañía Minera Hermosi- } \\
\text { llense, S. A. }\end{array}$ & 10000 & $\begin{array}{l}\text { Sociedad Minera "Sterling } \\
\text { Mines y Extensión" }\end{array}$ & 500 \\
\hline $\begin{array}{l}\text { Compañía Minera Hermosi- } \\
\text { llense, S. A. }\end{array}$ & 10000 & $\begin{array}{l}\text { Sociedad Minera de } \\
\text { Lampazos, S. N. C. }\end{array}$ & 1000 \\
\hline Compañía Minera Julia, S. A. & 1000 & $\begin{array}{l}\text { Sonora Exploration and } \\
\text { Metals Company, S. A. }\end{array}$ & 10000 \\
\hline $\begin{array}{l}\text { Compañía Minera la } \\
\text { Exploradora, S. A. }\end{array}$ & 10000 & Storman y Padilla, S. en C. & 16500 \\
\hline $\begin{array}{l}\text { Compañía Minera Nacional, } \\
\text { S. A. }\end{array}$ & 2000 & $\begin{array}{l}\text { Storman, Rodríguez y } \\
\text { Montijo, S. N. C. }\end{array}$ & 5000 \\
\hline $\begin{array}{l}\text { Compañía Minera Refugio, } \\
\text { Latz, Pearce y Compañía, } \\
\text { S. N. C. }\end{array}$ & 10000 & $\begin{array}{l}\text { Suaqui Grande Oro } \\
\text { Company, S. A. }\end{array}$ & 10000 \\
\hline $\begin{array}{l}\text { Compañía Minera San } \\
\text { Antonio, S. A. }\end{array}$ & 2000 dólares & $\begin{array}{l}\text { Teodoro Hoffmann y } \\
\text { Compañía, S. N. C. }\end{array}$ & 20000 \\
\hline $\begin{array}{l}\text { Compañía Minera y Fundidora } \\
\text { de Guasisaco, S. A. }\end{array}$ & 20000 & $\begin{array}{l}\text { The Barranca, Mines México, } \\
\text { S. A. }\end{array}$ & 50000 \\
\hline $\begin{array}{l}\text { Compañía Minera Zaragoza, } \\
\text { S. A. }\end{array}$ & 10000 & $\begin{array}{l}\text { The Mexican Mines } \\
\text { Company, S. A. }\end{array}$ & 10000 \\
\hline
\end{tabular}


Cuadro 2. Algunas empresas y negocios de capital (continuación)

\begin{tabular}{|l|c|l|c|}
\hline \multicolumn{1}{|c|}{ Nombre } & Capital social & \multicolumn{1}{|c|}{ Nombre } & Capital social \\
\hline $\begin{array}{l}\text { Compañía Naviera del Pacífico } \\
\text { (fusionadas las Línea de } \\
\text { Navegación del Pacífico y } \\
\text { Compañía de Transportes } \\
\text { Maritimos, formando esta } \\
\text { nueva compañía), S. A. }\end{array}$ & 1084000 & $\begin{array}{l}\text { The Sonora Gold and Silver } \\
\text { Mining Company, S. N. C. }\end{array}$ & 4500 dólares \\
\hline $\begin{array}{l}\text { Compañía Telefónica de } \\
\text { Sonora (ampliación), S. A. }\end{array}$ & 125000 & $\begin{array}{l}\text { The Yaqui River Land and } \\
\text { Irrigation Company, S. N. C. }\end{array}$ & 25000 \\
\hline $\begin{array}{l}\text { Creston Extention Mining } \\
\text { Company, S. A. }\end{array}$ & 5000 & $\begin{array}{l}\text { Von Güindell y Compañía, } \\
\text { S. N. C. }\end{array}$ & 30000 \\
\hline $\begin{array}{l}\text { E. Otero y Compañía, S. N. C. } \\
\text { [Brauer] }\end{array}$ & 23500 & $\begin{array}{l}\text { Y. Padilla y Compañía, } \\
\text { S. en C. [Storman] }\end{array}$ & 16500 \\
\hline $\begin{array}{l}\text { El Capitolio Mining Company, } \\
\text { S. A. }\end{array}$ & 2000 & & \\
\hline
\end{tabular}

S. N. C. es Sociedad en Nombre Colectivo; S. A. es Sociedad Anónima; S. en C. es Sociedad en Comandita.

* Aumento de capital; ** pesos oro.

FUENTE: Elaboración de Julieta López Griego a partir del Archivo General del Estado de Sonora, Fondo Notarías, y el Archivo General de Notarías del Estado de Sonora, Hermosillo.

En estepunto sigo la apreciación deBernd Hausberger cuando opina que

Una red es un sistema flexible y cambiante en el tiempo, una categoría esencialmente histórica, se caracteriza por su flexibilidad, por su función de enlace; está basada en la confianza mutua [y] se constituye en la compleja interacción con la familia, la etnicidad o la religión, es conservadora en cuanto a sus reglas [que] el individuo adapta y [está] en permanente negociación. ${ }^{29}$

No obstante, los negocios alemanes fueron afectados de manera desigual y faltan estudios para calibrar cómo y en qué medida el movimiento armado impactó a los alemanes en las diferentes regiones del país, entre éstas la frontera norte. Según Friedrich Katz, a partir de 1902-1903 el káiser alemán intentó adquirir extensos territorios en Baja California con el fin de instalar una base naval. En plena Revolución mexicana, el presidente del

29 Bernd Hausberger, "La conquista del empleo público en la Nueva España. El comerciante gaditano Tomás Ruiz de Apodaca y sus amigos, siglo XVIII”, Historia Mexicana, v. LVI, n. 3 (223), 2007, p. 730-731. 
Alldeutschen Verband Class y el embajador en México, Paul von Hintze, proyectaron una incursión militar hacia el norte. ${ }^{30} \mathrm{~A}$ partir de 1913 las familias alemanas y los descendientes nacidos en el país enfrentaron acusaciones y dudas sobre los verdaderos motivos de su estancia en el país, proceso que se repitió durante la Segunda Guerra Mundial. Empero, más allá del telegrama Zimmermann que generó tensiones entre México y Estados Unidos, la colonia alemana siguió creciendo sin cortapisas.

En la ciudad de México, por ejemplo, no hubo afectaciones significativas, incluso el Colegio Alemán aumentó su matrícula por los alumnos de otras regiones enviados a la capital del país, entre 1913 y 1920, para continuar sus estudios. Los agregados militares y culturales tampoco fueron afectados. Fue el caso del médico militar y espía Krumm Heller, quien daba clases en la Escuela Preparatoria Nacional. Expulsado del país por Victoriano Huerta volvió como agregado militar durante la presidencia de Venustiano Carranza y, más tarde, José Vasconcelos lo nombraría "representante universitario de México ante las Universidades de Austria y Alemania”. ${ }^{31}$

La presencia alemana en las Californias

Para el estudio del septentrión novohispano, la Alta Pimería y las Californias existe vasta documentación sobre viajeros centroeuropeos y misioneros jesuitas del imperio Habsburgo provenientes de Moravia, Bohemia, Croacia, Graz y Silesia. Destacan los estudios sobre Francisco Eugenio Kino, Juan Ratkay, Josef Neumann, Fernando Consag, Carlos Neumayer, Juan Xavier Bischof y otros provenientes de la Asistencia Germánica. Asimismo cinco jóvenes jesuitas destinados a las misiones de Nayarit en la primera mitad del siglo XVIII los referidos en el Catálogo dejesuitas dela provincia mexicana de 1761: Ignatius Tirsch y Václav Link. ${ }^{32}$

30 Friedrich Katz, Nuevos ensayos mexicanos, México, Era, 2006, p. 304.

31 Ricardo Pérez Montfort, “El Dr. Arnold Krumm-Heller. Un extraño ejemplo de alemán en México entre el esoterismo, el nacionalismo y la osmoterapia” en Brígida von Mentz, Babel. La comunidad alemana en la ciudad de México, México, Gobierno del Distrito Federal, Instituto de Cultura de la Ciudad de México, 1999, p. 21-38.

32 Otakar Odložilík, "Czech missionaries in New Spain”, The Hispanic American Historical Review, v. 25, n. 4, noviembre 1945, p. 428-454. Gerard Decorme, S. J., La obra de los jesuitas mexicanos durante la época colonial, 1572-1767, 2 v., México, Librería Robredo de José 
El aumento del comercio entre México y Alemania en el siglo XIX atrajo a alemanes asentados en Estados Unidos. Recuérdese que en octubre de 1683 llegaron una decena demenonitas y cuáqueros de Krefeld, Alemania, que se establecieron cerca de Filadelfia, en lo que fue conocido como Deutschstadt o Germantown. Con el tiempo fueron desplazándose hacia el centro y suroeste de los Estados Unidos y arribando por las costas mexicanas. ${ }^{33}$

Después de la consumación de la Independencia, aparecen registrados 168 extranjeros en la California mexicana. Para 1841 sumaban 228, la mayor parte estadounidenses (100), 24 ingleses, 21 franceses, 13 irlandeses, 9 escoceses, 4 alemanes, 3 italianos, 3 canadienses y con sólo un inmigrante aparecen originarios de Noruega, Portugal y Bélgica. En el mismo registro afloran otros 48 residentes que no declararon su origen y probablemente otros centroeuropeos. Una de las razones era que los avecindados se declaraban analfabetas y quienes los registraban tampoco eran muy perspicaces al momento de asentar el nombre y los apellidos. Como el caso de John Behn o Baden del imperio austriaco y John Gronigen tal vez holandés o alemán. ${ }^{34}$

A mediados del siglo XIX, la fiebre de oro en California atrajo una oleada de inmigrantes de Bremen al puerto de San Francisco y de ahí al sur de la antigua California mexicana. Entre otros extranjeros arribaron varios

Porrúa e Hijos, 1941. Ernest J. Burrus y Félix Zubillaga, El noroeste de México. Documentos sobre las misiones jesuíticas, 1609-1796, México, Universidad Nacional Autónoma de México, Instituto de Investigaciones Históricas, 1986. Juan Luis Maneiro, Vida de algunos mexicanos ilustres, México, Universidad Nacional Autónoma de México, 1988. María Cristina Torales Pacheco, “Los jesuitas y la Independencia de México: algunas aproximaciones", Destiempos, año 3, n. 14, marzo-abril, 2008, p. 397-412. Simona Binkova, “El padre Wenceslao Linck, explorador del norte de la Antigua California, entre el P. Fernando Consag y fray Junípero Serra" en Carlos Lazcano Sahagún (coord.), Homenaje a Fernando Consag, S. J., 1703-1759, México, Fundación Barca/Agrotécnica de San Quintín/Sociedad de la Antigua California, 2011, p. 139-168.

33 Eberhard Reichmann, La Vern J. Rippley \& Jörg Nagler (eds.), Emigration and settlement patterns of German communities in North America, Indianápolis/Nashville, Indiana University/Purdue University, 1995. En los archivos nacionales de la Librería del Congreso, en Washington se encuentran las listas de pasajeros alemanes que llegaron a costas estadounidenses entre los siglos XVII y XX, contabilizándose ocho millones de inmigrantes. Véase también Michael P. Palmer, German and American Sources for German Emigration to America, en http://www.genealogienetz.de/misc/emig/emigrati.html.

34 Elizabeth R. Rhoades, Foreigners in Southern California during the Mexican period, tesis, San Francisco, Universidad de California, 1924, [reimpreso en 1971 por R. and E. Research Associates, San Francisco, California], p. 2-3, p. 170. 
alemanes que viajaron desde el levante estadounidense a establecerse en las costas del alto Pacífico mexicano. Entre otros, el carpintero que erigió la casa de Francisco García, juez en Monterey, California, entre 1848 y 1850. Esa preciosa edificación se transformaría en el Hotel Bay View House, cuando la región fue arrebatada a México por los estadounidenses..$^{35}$ Los alemanes asentados en el viejo pueblo de San Diego acostumbraban pescar cerca de Ensenada, Baja California, y congeniaron con otros compatriotas establecidos en el pequeño puerto mexicano; algunos con casas comerciales y negocios bien establecidos como Melchers Sucesores, J orge Ibs y Compañía, C. Goldschmidt y Luis Hüller.

Este último, naturalizado estadounidense, obtuvo una concesión para colonizar 5395 hectáreas y explotar minas de oro, plata, azufre y guano en el Distrito Norte de Baja California. Hüller fue el mismo que vendió lotes de 2500 hectáreas en Chiapas, entre 1896y 1905, "sin respetar la cláusula de nacionalidad mexicana del comprador, 80 por ciento de las propiedades pasaron a cafetaleros extranjeros, en su mayoría alemanes". ${ }^{36}$

Poco antes de que México perdiera la Alta California se contabilizaron 162 residentes de origen alemán en el viejo pueblo de San Diego, algunos dedicados al comercio como Joseph S. Mannase, Marcus Schiller o David Fensenheld, quienes poblarían con sus familias el New Town. Con el tiempo, edificaron una sinagoga, el club Teutonia Verain y el inmueble de la Cámara de Comercio de San Diego. En 1885, la colonia alemana contaba con un cónsul (honorario) en la región, Arnold Wentscher, 300 coterráneos y un espacio de 18000 kilómetros cuadrados (4431 acres) detierra con los que formaron el asentamiento Olivenhain, a 8 kilómetros del rancho Las Encinitas, California, que aún existe. ${ }^{37}$ Del mismo modo fundaron el periódico The Sud-California Deutsches Zeitung, erigieron la Iglesia Episcopal

35 Anónimo, California History. The Journal of the California Historical Society, Special Feature, Briding The Golden Gate. A Photo Essay, v. 89, n. 3, 2012, p. 6.

36 Antonio García de León, Resistencia y utopía. Memorial de los agravios y crónica de revueltas y profecías acaecidas en la provincia de Chiapas durante los quinientos años de su historia, México, Era, 1997, p. 178. Hillarie J. Heath, “La época de las grandes concesiones, 1883-1910" en Catalina Velázquez (coord.), Baja California, un presente con historia, México, Universidad Autónoma de Baja California, 2002, v. I, p. 247-300.

37 El Consulado se transfirió a Los Ángeles y hasta 1963 se abrió una nueva representación en San Diego. Elizabeth Reinbold MacPhail, The influence, p. 15-43. 
Metodista Alemana, una amplia factoría para confeccionar tabaco y lugares de recreo aprovechando las aguas minerales subterráneas que cruzaban ambos lados de la frontera (Carlsbad y Agua Caliente).

En Baja California es probable que hubiese una treintena dealemanes o de sus descendientes en las postrimerías del siglo XIX por la actividad comercial desde Mazatlán hacia la península (cuadro 3). Las fuentes históricas sugieren que durante la década revolucionaria (1910-1920) más de una centena de alemanes llegaron por diferentes motivos a los poblados de la frontera norte mexicana - incluidas las localidades de Mexicali, Tijuana y Ensenada-. Hubo inclusive aprehensiones por robo y rebelión del alemán-estadounidense Félix Wirbser, propietario del Hotel Bay View y copropietario del Hotel Hidalgo, en el puerto de Ensenada en 1912. Asimismo hubo seguimiento puntual de actividades "sospechosas" de alemanes, como Virginio Bernier y los hermanos Heinrich y Abraham Defehr, agricultores asentados en la colonia agrícola rusa en Valle de Guadalupe. ${ }^{38}$

Posteriormente a la Primera Guerra Mundial, continuó registrándose en la documentación oficial la presencia de población de lengua alemana en la península. Aparecen, por ejemplo, el artista austriaco Darío Rappaport y su esposa Anita Hermann, quienes cruzaron la frontera por Mexicali entre 1929 y 1930; Heinrich Scheinehotz, H. Nevill, Curt y Félix Effler con destino a Ensenada, ${ }^{39}$ así como los negocios de la familia Hussong - que refiero en el siguiente apartado-, los del coronel Esteban Cantú y las ofertas al general Abelardo L. Rodríguez, gobernador y jefe militar en Baja California y luego presidente de la República por unos meses.

En ese lapso varios alemanes se acercaron a Rodríguez para plantearle negocios conjuntos: $\mathrm{H}$. von Holleuffer, berlinés gerente de Comercio Internacional, puso a consideración de Rodríguez la compra de algodón de Mexicali, mientras Baruth Urbach, de Los Ángeles, California, propuso

38 Elizabeth Reinbold MacPhail, The influence, p. 12. "Informe sobre conducta y antecedentes del señor Félix Wirbser”, Acervo Documental del Instituto de Investigaciones Históricas, UABC (en adelante, ADIIH-UABC), Colección AGN, Fondo Dirección General de Gobierno, Mexicali, 8 de abril de 1925, c. 1, exp. 49. “Informe sobre el alemán Abraham Defehr”, ADIIH-UABC, Colección AGN, Fondo Dirección General de Gobierno, 24 de marzo de 1925, c. 7, exp. 52. “Informes sobre el alemán Heinrich Defehr”, ADIIH-UABC, Colección AGN, Fondo Dirección General de Gobierno, Tijuana, 8 de abril de 1925, c. 7, exp. 53.

39 Archivo de la Secretaría de Relaciones Exteriores, inventario IV/551.2 (73-6)1 y IV/386-1. 
Cuadro 3. Compraventa de harina procesada de residentes en Baja California (1886)

\begin{tabular}{|c|c|c|}
\hline Remitente & Destino & Consignatario \\
\hline Andonaegui y Ormart & Cabo San Lucas & Ildefonso Green \\
\hline Andonaegui y Ormart & La Paz & Ignacio Romero \\
\hline Andonaegui y Ormart & La Paz & Hidalgo y Compañía \\
\hline Andonaegui y Ormart & Mazatlán & Tamés Elorza y Compañía \\
\hline Andonaegui y Ormart & Mazatlán & Mateo Magaña \\
\hline F. Ryerson & Bahía Magdalena & Flores Hale y Compañía \\
\hline F. Ryerson & La Paz & Ignacio Romero \\
\hline G. Villarino & La Paz & González y Ruffo \\
\hline J. F. Ruiz & La Paz & Gilberto Padilla \\
\hline J.H. Hidalgo & La Paz & Gilberto Padilla \\
\hline Jesús Legaspy & Cabo San Lucas & Jesús Legaspy \\
\hline Jordán Félix & La Paz & Agustín Arriola \\
\hline Jorge Ibs y Compañía & Bahía Magdalena & G. Hale \\
\hline Jorge Ibs y Compañía & Bahía Magdalena & Melchers Sucesores \\
\hline Jorge Ibs y Compañía & Cabo San Lucas & Jorge Ibs y Compañía \\
\hline Jorge Ibs y Compañía & Cabo San Lucas & M. Salgado \\
\hline Jorge Ibs y Compañía & La Paz & Cabezud y Compañía \\
\hline Jorge Ibs y Compañía & Mazatlán & C. Goldschmidt \\
\hline Jorge Ibs y Compañía & Mazatlán & Melchers Sucesores \\
\hline Mateo Magaña & Mazatlán & Mateo Magaña \\
\hline
\end{tabular}

colonizar la zona del valle de Mexicali con judíos alemanes. Ambos asuntos no prosperaron. ${ }^{40}$ En resumen, desde finales del Porfiriato hallamos a la comunidad alemana en California, Estados Unidos, y los distritos Norte y Sur de Baja California, México.

40 "Carta de H. von Hollefuffer al gobernador de Baja California Agustín Olaechea”, 9 de enero de 1933, ADIIH-UABC, Colección AGN, Fondo Abelardo L. Rodríguez, c. 6, exp. 24. "Carta de Baruth Urbach a Abelardo L. Rodríguez”, 29 de mayo de 1933, ADIIH-UABC, Colección AGN, Fondo Abelardo L. Rodríguez, C. 5, exp. 28. 
Alemanes en la península. A manera de conclusión

Según algunos cálculos, para el año 1871 había en México aproximadamente 1500 alemanes. La tercera parte de ellos vivía en la capital del país y el resto se hallaban dispersos a lo largo del territorio. En 1895 el número había ascendido a 2420 alemanes y 65 por ciento de ellos se dedicaba al comercio. En una fracción de la antigua California mexicana destacaban Abraham Klauber, Simón Levi, Isador Louis - conocido como "el padre del helado" en San Diego- y los hermanos Leopoldo, José y Frank Winter, quienes establecieron casas comerciales y empresas para la distribución del gas, la telefonía, la confitería y la repostería.

En el caso de la península de Baja California hay pocos estudios sobre los alemanes y sus descendientes pero sabemos de la actividad comercial desarrollada por algunos. Por ejemplo, tenemos información de los comerciantes Parnow Leben de La Paz, Francisco Fischer de San Ignacio y Enrique A. von Borstel de San José del Cabo, quien también denunció para su explotación la mina de Santa Anna, ${ }^{41}$ los tres casos en la actual Baja California Sur. En el norte de la península hallamos al mencionado colonizador de Ensenada Luis Hüller y su apoderado Maximiliano Bernstein. A Jorge Ibs, Andrés Strickroth, los cerveceros John Tischhauser y Frit Walde, así como a la familia política del coronel Esteban Cantú, los Dato (Pablo, Pablo hijo, Guillermo, Gustavo y Federico), enganchadores de jornaleros chinos para los campos de Mexicali, con intereses en la pesca, la peletería y el comercio durante la jefatura política del neoleonés.

La historiadora Cristina Ortiz Manzo reconstruye actualmente la trayectoria empresarial de la familia Lutteroth, con presencia en toda la península, el estado de Sonora y la capital del país, y negocios que incluyen la lucha libre y los espectáculos en el siglo Xx.

Otros casos de alemanes en la región fueron los traductores, los brókeres, los ganaderos y los apoderados legales en Baja California. Por ejemplo, Luis Mendelson, originario de Polonia pero cuya lengua materna era el alemán y avecindado en Real del Castillo, fue comerciante y síndico del 
primer ayuntamiento de Ensenada. Este personaje sería acusado luego del delito de sedición, en agosto de 1882, junto con Lorenzo Guarello -de ascendencia italiana-, George Ryerson, Ramón A. Rodríguez y Joaquín Altamirano, residentes en Ensenada. ${ }^{42}$ Encontramos también a maestros cerveceros en ambos lados de la frontera binacional: los hermanos Mayrhofer que establecieron la cervecera Biergarten de San Diego, "la más grande de la costa del Pacífico" y otra en el poblado Julián del mismo condado de California, ${ }^{43}$ además a J ohn Tischhauser, de la Cervecería Ensenada, y a Curt Grutzbach, cervecero establecido en Mazatlán en 1931, quien llegaría más tarde a Baja California. ${ }^{44}$

Referí al inicio de esteestudio quea lo largo delainvestigación hallamos muchos otros personajes sin vínculos importantes con la actividad económica o empresarial en la región, como el escritor berlinés Reinhard Braun, asentado en Santa Mónica, California, y mecenas devarios artistas con quienes cruzaba la frontera binacional durante la etapa de la prohibición. Así como Otto Schmidt instructor de educación física que introdujo con otros compatriotas las human flag o tablas gimnásticas en los Juegos Olímpicos de $1928 .{ }^{45}$ Aquellos actores merecen un estudio aparte, por lo que melimito a concluir con dos experiencias empresariales de alemanes en el noroeste mexicano que son notas de trabajo, como advierte el título del artículo.

La experiencia del comerciante alemán J orge Ibs (George Ibs, 18491921) es un botón de muestra de la ruta tradicional de migración alemana a fines de la década 1860: Veracruz, ciudad de México, Mazatlán y Baja California. Los jóvenes alemanes llegaban al nuevo mundo invitados por algún familiar o paisano y se empleaban en las casas comerciales o negocios establecidos. Al vivir con sus paisanos en el mismo almacén y ser considerados "casi de la familia", los jóvenes ahorraban buena parte de su sueldo para independizarse y fundar un negocio propio. El salto del socio comanditario al socio capitalista era lo más común, dejar de ser depen-

42 "Proceso Grutzbach" en Archivo Histórico del Poder Judicial de la Federación, Fondo Casa de la Cultura Jurídica, Tijuana, c. 3, exp. 19.

43 Elizabeth Reinbold MacPhail, The influence, p. 55.

44 Sobre el hábito cultural de beber de los alemanes para diferenciarse de sus vecinos holandeses, franceses e ingleses, vid. Norbert Elias, Los alemanes, México, Instituto de Investigaciones Dr. José María Luis Mora, 1999, introducción.

45 Cfr. Elizabeth Reinbold MacPhail, The influence, p. 68 y $82-87$. 
diente del negocio a socio menor y representante del negocio en las regiones más alejadas. ${ }^{46}$

J orge Ibs se estableció en el partido sur de Baja California y más tarde se mudó al Distrito Norte. ${ }^{47}$ Las primeras noticias de Ibs se registran en San José del Cabo, luego en Ensenada, Tijuana y San Diego, California. En San J osé fundó la J orge Ibs \& Company, para la atención de los rancheros y los comerciantes locales, avituallado negocio donde ofreció mercancías y avío a los mineros, así como alojamiento y servicios. Al parecer, Ibs fue dueño del hotel Miramar de Ensenada y continuó con la venta de harina procesada en el intercambio con los consignatarios que tenía en Mazatlán, entre otro Melchers y Sucesores, también de origen alemán. El libro de cuenta corriente de Ibs y Compañía constata que entre 1892 y 1895 vendía a crédito, a un plazo de cuatro meses y una tasa del 12 por ciento anual. El cobro correspondiente generó también inconvenientes, porque Jorge Ibs \& Company entabló juicio en contra de H. H. Cannon, dela población de San Quintín, por adeudos vencidos y algunos otros que no siempre ganó.

J orge Ibs contrajo nupcias con Ludmilla Ermendberg y tuvieron dos hijas en territorio mexicano: Ella - nacida en San J osé del Cabo el 13 de diciembre de 1878- y Matilde. La primera de ellas se casó con el sonorense Miguel González, uno de los primeros comerciantes dedicados a atender el turismo de Ensenada y Tijuana, por lo quela experiencia del alemán fue bien aprovechada por González. Sin embargo, Ibs murió sin dejar testamento en abril de 1921, en San Diego, California. ${ }^{48}$ El proceso judicial correspondiente incluyó la convocatoria a sus familiares en el país y fuera de él, de ahí que apareciera publicada la noticia en el Periódico Oficial de Baja California, en el Hispano Americano de San Diego, California, y en el Die Marner Zeitung de Hamburgo en febrero de 1925.

46 Sergio Valerio, loc. cit. Consuelo Delgado y J. Rafael Sáenz, loc. cit.

47 La península de Baja California se dividió administrativamente en dos partidos (norte y sur) en 1850 . En 1888 las dos fracciones tomaron el nombre de distritos (norte y sur) hasta 1920. Entre 1920 y 1931 las delegaciones que conformaron el Distrito Norte funcionaron como ayuntamientos hasta que en 1952 se declaró entidad federativa a Baja California con legislatura y gobernador propios.

48 "Juicio testamentario y notificaciones por el deceso del señor Jorge Ibs", ADIIH-UABC, Colección Archivo Judicial de Ensenada, c. 147, exp. 5. 
La crónica local acepta que J orge Ibs se integró a la comunidad peninsular y fronteriza a través de los nodos de las redes familiares y empresariales de la época, los negocios con paisanos o coterráneos y el casamiento de las hijas para preservar el negocio. Con el tiempo, el negocio quedó en manos de uno de los nietos de Ibs, quien no pudo o no quiso seguir administrando lo que significó tanto esfuerzo para un inmigrante que hizo de la región su casa y su espacio en el mundo.

El último caso de este estudio es el relato de la familia Hussong, empresarios de los poblados de Ensenada y Ojos Negros, Baja California, con presencia en San Diego, California, una experiencia opuesta a la anterior ya que van por la cuarta generación que conservan la actividad comercial, si bien algunos de los bisnietos se han mudado de la región y elegido otro tipo de actividades profesionales como proyecto de vida. Los Hussong han diversificado su actividad comercial a lo largo del tiempo, desde la importación y exportación de licores, la pesca, la generación de energía eléctrica, la hotelería, la radiodifusión hasta la venta de refacciones para automóvil, estaciones de gasolina, la pintura y la viticultura.

El inicio del relato surge con el alemán J ohan oJ ohn Hussong (18641926) originario de Rheinland-Pfalz (Renania-Palatinado), quien desarrolló el comercio en pequeño, la importación-exportación delicoresy bebidas espirituosas así como la hotelería y los servicios. Sus padres fueron Ludwig J ohan Hussong y Louisa Hahn, quienes llegaron a Nueva York con otros familiares, se movieron al oeste de Estados Unidos y deahí se establecieron en la península de Baja California. Las primeras noticias de John Hussong aparecen en Real del Castillo, antigua cabecera del Partido Norte de Baja California, cuya principal actividad fue la minería de oro y el comercio hacia San Diego, California.

La cabecera municipal se mudó al puerto de Ensenada en 1882 y el alemán también trasladó su comercio a ese nuevo espacio con el agregado de una mesa de billar para el solaz de la clientela. La inversión que le permitió despuntar fue la compra de terrenos, y avanzado el siglo XX el negocio familiar se extendió hacia la radiodifusión, la venta de refacciones para automóvil, el establecimiento de estaciones de gasolina, la venta de souvenirs y sobre todo la famosa e histórica cantina Hussong, que sigue en pie como atractivo turístico en el corredor comercial de Ensenada. 
J ohn Hussong formó una familia estable con María Luisa Ortell (Forchheim, Bayern, 1862) y el emporio comercial fue creciendo junto con sus hijos Ricardo, Estela, Percy, J uan -J ohn junior- , Ricardo y J orge Walter (1907). En las décadas 1920 y 1930 los Hussong se relacionaron con los "grandes empresarios" de la región, la familia Sandoval, los Salazar, los Peterson, los Ceseña y el gobernador del Distrito y luego presidente de México, Abelardo L. Rodríguez. Estas redes sin lugar a dudas tuvieron influencia en el empresariado y la política de la región a mitad del siglo XX. No obstante, la Segunda Guerra Mundial les acarreó dolores de cabeza a los Hussong, como a buena parte de los alemanes y sus descendientes en aquellos años.

Una de las experiencias más difíciles fue la acusación contra Percy Hussong, "el más agitador de la familia", según el informante de la Secretaría de Gobernación comisionado en el puerto de Ensenada. En 1939 el gobierno federal detuvo a Percy y lo fichó como "germanófilo, simpatizante de las ideas alemanas e inmiscuido en actividades sospechosas en los alrededores de San Felipe, Baja California”. Las actividades sospechosas fueron el traslado de toneles de gasolina como parte de los negocios familiares. A pesar de esto, un cónsul de México argumentó que Percy utilizaba dos alias - J ohn Martin y George Hamilton- para moverse entre México y Estados Unidos. ${ }^{49}$

La posibilidad de reconstruir las redes empresariales y familiares a partir de estos personajes, así como relatos particulares de los mexicanos de ascendencia alemana en el noroeste de México es una tarea pendiente.

49 “Informe de Eliseo Ruiz Russek, cónsul de México, sobre las actividades de Percy Hussong, alias John Martin, y George Hamilton, febrero de 1943", en AGN, Fondo Investigaciones Políticas y Sociales, c. 2560. Se refieren a Percy Hussong Domínguez, tal vez hijo de Percy y nieto de John Hussong. En este sentido, la reconstrucción de lo acontecido durante la Segunda Guerra Mundial está por escribirse, así como los yerros permanentes de los agentes de Gobernación que "vigilaban” a los extranjeros en el país. Por ejemplo, el seguimiento al anciano de origen alemán Hubert Hansen, calumniado de espionaje y de montar y cuidar una estación de radio en La Rumorosa, Baja California, entre mayo y junio de 1942. Por esos días un hijo de Hansen fue asesinado "por un extraño", y se extendió el rumor de que fue porque ellos tenían "las claves telegráficas” para comunicarse con los nazis. En realidad se trataba de un pobre trabajador de la Compañía Jabonera de Mexicali. 
Fuentes

Archivos consultados

Acervo Documental del Instituto de Investigaciones Históricas, Universidad Autónoma de Baja California, Colecciones Archivo Judicial de Ensenada y Archivo General de la Nación

Archivo de la Secretaría de Relaciones Exteriores

Archivo General de la Nación (Ciudad de México)

Departamento de Migración

Sección Alemanes

Investigaciones Políticas y Sociales

Archivo Histórico del Poder Judicial de la Federación, Suprema Corte de

J usticia de la Nación, Casa de la Cultura J urídica, Tijuana

Bibliografía

Bernecker, Walther L., Contrabando. Ilegalidad y corrupción en el México del siglo XIX, México, Universidad Iberoamericana, 1994. , "Las relaciones comerciales germano-mexicanas en el siglo XIX" en León Bieber (coord.), Las relaciones germano-mexicanas desdeel aporte de los hermanos Humboldt hasta el presente, México, El Colegio de México/Universidad Nacional Autónoma de México, Facultad de Filosofía y Letras, 2002.

, “Los alemanes en el México decimonónico: desdela Independencia hasta la Revolución de 1910" en Karl Kohut et al., Alemania y el México independiente. Percepciones mutuas, 1810-1910, México, Herder/Centro de Investigaciones y Estudios Superiores en Antropología Social/Universidad Nacional Autónoma de México/Universidad Iberoamericana/Cátedra Guillermo y Alejandro von Humboldt, 2010.

Binkova, Simona, "El padre Wenceslao Linck, explorador del norte de la Antigua California entre el P. Fernando Consag y fray Junípero Serra" en Carlos Lazcano Sahagún (coord.), Homenaje Fernando Consag, S. J.1703-1759, México, Fundación Barca/Agrotécnica de San Quintín/ Sociedad de la Antigua California, 2011.

Böhme, Helmut, "Prolegomena zu einer Sozial-und Wirschaftsgeschichte Deustchland im 19. und 20.", en Jahrhundert, Frankfurt, 1968. 
Burrus, Ernest J. y Félix Zubillaga, El noroeste de México. Documentos sobre las misiones jesuíticas, 1609-1796, México, Universidad Nacional Autónoma de México, Instituto de Investigaciones Históricas, 1986.

Castellanos Cambranes, J ulio, El imperialismo alemán en Guatemala. El Tratado de Comercio de 1887, Guatemala, Universidad de San Carlos de Guatemala, Instituto de Investigaciones Económicas y Sociales, 1977.

Dane, Hendrik, Die wirtschaftlichen Beziehungen Deustschlands zu Mexiko und Mittelamerica im 19 Jahrhundert, Colonia, Böhlau Verlag, 1971.

Decorme, Gerard, S.J., La obra de los jesuitas mexicanos durante la época colonial, 1572-1767, 2 v., México, Librería Robredo de José Porrúa e Hijos, 1941.

Delgado Cortina, Consuelo y J. Rafael Sáenz R., "La oligarquía empresarial alemana en Colima, siglos XIX y Xx" en Memoria del IV Foro Colima y su Región. Arqueología, antropología e historia, México, Gobierno del Estado de Colima, Secretaría de Cultura, 2008.

Devoto, Fernando, Historia de la inmigración en la Argentina, Buenos Aires, Sudamericana, 2009.

Durán-Merk, Alma, Identifying Villa Carlota: German settlements in Yucatán, Mexico, during the Second Mexican Empire 1864-1867, Augsburg, Universität Augsburg, 2007.

Elias, Norbert, Los alemanes, México, Instituto de Investigaciones Dr. José María Luis Mora, 1999.

García de León, Antonio, Resistencia y utopía. Memorial de los agravios y crónica de revueltas y profecías acaecidas en la provincia de Chiapas durante los quinientos años de su historia, México, Era, 1997.

Gallero, María Cecilia, Con la patria a cuestas. La inmigración alemanabrasileña en la Colonia Puerto Rico, Misiones, Buenos Aires, Araucaria, 2009.

González Herrera, Carlos, "De Franklin a El Paso. La transformación de un asentamiento mexicano en una ciudad angloamericana: 1850-1910" en Jorge Chávez (comp.), Visiones de la frontera, México, Universidad Autónoma de Ciudad Juárez, 2010.

Heath, Hillarie J., "La época de las grandes concesiones, 1883-1910" en Catalina Velázquez (coord.), Baja California, un presente con historia, México, Universidad Autónoma de Baja California, 2002, t. I.

Katz, Friedrich, La guerra secreta en México, 2 v., México, Era, 1982, v. I. Nuevos ensayos mexicanos, México, Era, 2006. 
Kohut, Karl et al., Alemania y el México independiente. Percepciones mutuas, 1810-1910, México, Herder/Centro de Investigaciones y Estudios Superiores en Antropología Social/Universidad Nacional Autónoma de México/Universidad Iberoamericana/Cátedra Guillermo y Alejandro von Humboldt, 2010.

Lloyd, Jane-Dale, Cinco ensayos sobre cultura material de rancheros y medieros del noroeste de Chihuahua, 1886-1910, México, Universidad Iberoamericana, 2001.

MacPhail, Elizabeth Reinbold, The influence of German immigrants on the growth of San Diego, San Diego, San Diego Historical Society, 1986.

Maneiro, J uan Luis, Vida de algunos mexicanos ilustres, México, Universidad Nacional Autónoma de México, 1988.

Méndez Reyes, Jesús, "La Secretaría de Gobernación y el control político y económico en México durante el siglo XIX" en Historia de la Secretaría de Gobernación, México, Instituto Nacional de Estudios Históricos de la Revolución Mexicana, 2000, v. III.

Mentz, Brígida von et al., Los pioneros del imperialismo alemán en México, México, Centro de Investigaciones y Estudios Superiores en Antropología Social, Ediciones de la Casa Chata, 1982.

Mentz, Brígida von (coord.), Movilidad social de sectores medios en México. Una retrospectiva histórica. Siglos XVII al XX, México, Centro de Investigaciones y Estudios Superiores en Antropología Social/Miguel Ángel Porrúa, 2003.

Meyer, Rosa María, "El estilo empresarial de especular. Nacionalidad y finanzas a mediados del siglo XIX" en Rosa María Meyer et al., Los inmigrantes en el mundo de los negocios, México, Plaza y Valdés/ Consejo Nacional para la Cultura y las Artes/Instituto Nacional de Antropología e Historia, 2003.

Monroy Castillo, María Isabel, Sueños, tentativas y posibilidades. Extranjeros en San Luis Potosí, 1821-1845, México, El Colegio de San Luis/ Archivo Histórico del Estado de San Luis Potosí, 2004.

Ortoll, Servando, Las conquistas y desventuras de un cónsul y hacendado alemán en Colima, Hermosillo, El Colegio de Sonora, 2005.

Pérez Montfort, Ricardo, “El Dr. Arnold Krumm-Heller. Un extraño ejemplo de alemán en México entre el esoterismo, el nacionalismo y la osmoterapia” en Brígida von Mentz, Babel. La comunidad alemana en la ciudad de México, México, Gobierno del Distrito Federal, Instituto de Cultura de la Ciudad de México, 1999. 
, “Un siglo y medio de presencia germana en la capital”, en Carlos Martínez Assad (coord.), La ciudad cosmopolita de los inmigrantes, 2 v., México, Gobierno del Distrito Federal, 2009.

Pietschmann, Horst, "Paralelismos y percepciones mutuas en el proceso de formación de la representación político-democrática en México y Alemania en el primer tercio del siglo XIX" en Karl Kohut et al., Alemania y el México independiente. Percepciones mutuas, 1810-1910, México, Herder/Centro de Investigaciones y Estudios Superiores en Antropología Social/Universidad Nacional Autónoma de México/Universidad Iberoamericana/Cátedra Guillermo y Alejandro von Humboldt, 2010. Preciado Llamas, J uan, En la periferia del régimen. Baja California Sur durante la administración porfirista, La Paz, Gobierno del Estado de Baja California Sur, Instituto Sudcaliforniano de Cultura, 2005.

Reichmann, Eberhard, La Vern J. Rippley y Jörg Nagler (eds.), Emigration and settlement patterns of German communities in North America, Indianápolis/Nashville, Indiana University/Purdue University, 1995. Rhoades, Elizabeth R., Foreignersin Southern California during theMexican period, tesis, San Francisco, Universidad de California, 1924 [reimpreso en 1971 por R. and E. Research Associates, San Francisco, California.]

Sáenz Rangel, José Rafael, "La población alemana en Colima durante el Porfiriato: profesión e integración a la economía regional” en J. Carlos Reyes G. (ed.), Memoria del III Foro Colima y su Región. Arqueología, antropología e historia, México, Gobierno del Estado de Colima, Secretaría de Cultura, 2007.

Salazar, Delia, Las cuentas de los sueños. La presencia extranjera en México a través de las estadísticas nacionales, 1880-1914, México, Secretaría de Gobernación, Instituto Nacional de Migración/Instituto Nacional de Antropología e Historia/DGE, 2010.

Stalker, Peter, Workers without frontiers: The impact of globalization on international migration, Boulder, Lynne Rienner, 2000.

Steinberg, J onathan, Bismarck, a life, Nueva York, Oxford University Press, 2011.

Torales, María Cristina, "La colonia alemana en la capital mexicana decimonónica. La construcción de su imagen pública” en Karl Kohut et al., Alemania y el México independiente. Percepciones mutuas, 1810-1910, México, Herder/Centro de Investigaciones y Estudios Superiores en Antropología Social/Universidad Nacional Autónoma de México/Universidad Iberoamericana/Cátedra Guillermo y Alejandro von Humboldt, 2010. 
Valerio Ulloa, Sergio, Los empresarios extranjeros en Guadalajara durante el Porfiriato, Guadalajara, Universidad de Guadalajara, 2002.

Revistas, publicaciones periódicas, otros

Alcaraz, Yetlaneci, "Huida a México", Proceso, n. 1888, 6 de enero de 2013. Anónimo, California History. The Journal of the California Historical Society, Special Feature, Briding The Golden Gate. A Photo Essay, v. 89, n. 3, 2012.

Hausberger, Bernd, "La conquista del empleo público en la Nueva España. El comerciante gaditano Tomás Ruiz de Apodaca y sus amigos, siglo XVIII", Historia Mexicana, v. LVI, n. 3 (223), 2007.

Hochstadt, Steve, "Migration in Preindustrial Germany" en Conference Group for Central European History of the American Historical Association, en www.jstor.org/stable/4545987, consultado 27 de noviembre de 2012.

López Griego, Julieta y J. Méndez Reyes, “Alemanes en el noroeste mexicano: redes empresariales en Sonora y Baja California a fines del XIX. Una aproximación" en XXIV Simposio de Historia, Sociedad Sonorense de Historia, A.C., Hermosillo, Sonora, noviembre de 2011, inédito.

Méndez Reyes, Jesús, “Alemania y México, una relación histórica. La influencia alemana en el cooperativismo y el crédito agrario en México", Matices Zeitschrift zu Lateinamerika, Spanien und Portugal, Colonia, n. 64, 1, 2010.

Mentz, Brígida von, “Tecnología minera alemana en México durante la primera mitad del siglo XIX", Estudios de Historia Moderna y Contemporánea, v. 8,1980 .

Odložilík, Otakar, "Czech Missionaries in New Spain”, The Hispanic American Historical Review, v. 25, n. 4, noviembre, 1945, p. 428-454.

Serrano Álvarez, Pablo, "Hacendados, comerciantes y empresarios extranjeros en Colima, 1857-1914", Revista del Seminario de Historia Mexicana, v. III, n. 2, verano 2002.

Stuke, Horts, The Economic History Review, New Series, v. 24, n. 2, 1971. Torales Pacheco, María Cristina, “Los jesuitas y la Independencia de México: algunas aproximaciones", Destiempos, año 3, n. 14, marzo-abril 2008. Vieyra, Lilia y Alejandro Vigil, “Isidoro Epstein: un alemán en México (1851-1894)”, Boletín, v. XI, n. 1 y 2, 2006. 